\title{
Caracterização molecular de acessos de mandioca biofortificados com potencial de uso no melhoramento genético ${ }^{1}$
}

\author{
Molecular characterization of biofortified cassava accessions with potential for use in \\ genetic improvement
}

\author{
Eduardo Alano Vieira ${ }^{2 *}$, Josefino de Freitas Fialho ${ }^{3}$, Fabio Gelape Faleiro ${ }^{2}$, Graciele Bellon ${ }^{4}$ e Marilia Santos \\ Silva ${ }^{2}$
}

\begin{abstract}
Resumo - A mandioca apresenta potencial como fonte de carotenóides na alimentação humana, em especial $\beta$-caroteno (nas raízes amarelas) e licopeno (nas raízes rosadas). Assim, a possibilidade da mandioca ser, além de fonte de calorias, uma fonte de vitaminas e antioxidantes, é encarada como forma de melhorar a nutrição dos habitantes de países em desenvolvimento. Neste trabalho, objetivou-se caracterizar por meio de marcadores RAPD 20 acessos de mandioca biofortificados com potencial de uso no melhoramento genético. Os acessos foram avaliados por meio de marcadores RAPD, sendo posteriormente estimada a matriz de similaridade genética entre os acessos, por meio do índice de Jaccard. A análise por meio de 12 iniciadores gerou um total de 144 bandas das quais 120 (83\%) foram polimórficas. A análise de agrupamento revelou a formação três grupos, sendo o grupo um formado por sete acessos com cor da polpa da raiz rosada e dois acessos com cor da polpa da raiz amarela, o grupo dois formado por oito acessos com cor da polpa da raiz amarela e um acesso com cor da polpa da raiz rosada e o grupo três formado pelos acessos melhorados com cor da polpa da raiz creme e branca. Os marcadores RAPD foram eficientes na determinação da variabilidade genética entre acessos de mandioca com cor da polpa da raiz amarela, rosada, creme e branca, diferenciaram os acessos melhorados dos demais acessos e revelaram uma tendência de separação dos acessos com cor da polpa da raiz rosada dos com a cor da polpa da raiz amarela.
\end{abstract}

Palavras-chave - Manihot esculenta Crantz. Variabiliade genética. Marcadores moleculares. Recursos genéticos.

\begin{abstract}
Cassava presents potential as source of carotenoids for human diet, in special $\beta$-carotene (within the yellow roots) and lycopene (within the pinkish roots). So, the possibility for cassava to be, besides source of calories, source of vitamins and antioxidants as well is faced as a manner to improve the nutrition of inhabitants of developing countries. In the present work, the aim was to characterize by RAPD markers 20 accessions of biofortified cassava with potential for use in genetic improvement. The accessions were evaluated via RAPD markers, being then estimated the matrix of genetic similarity among the accessions by using the Jaccard index. The analysis using 12 primers generated a total of 144 markers, among which $120(83 \%)$ were polymorphic. The clustering analysis revealed the formation of three groups, being group one formed by seven accessions with pinkish root pulp and two with yellow root pulp, group two formed by eight accessions with yellow root pulp and one accession with pinkish root pulp, and group three formed by improved accessions with either cream color or white root pulp. The RAPD markers were efficient to determine the genetic variability among the cassava accessions with yellow, pinkish, cream color and white root pulp, differentiated the improved accessions from the others and revealed a trend to separate the accessions with pinkish root pulp from the accessions with yellow root pulp.
\end{abstract}

Key words - Manihot esculenta Crantz. Genetic variability. Molecular markers. Genetic resources.

\footnotetext{
* Autor para correspondência

${ }^{1}$ Recebido para publicação em 31/08/2010; aprovado em 14/03/2011

Pesquisa financiada com recursos da Embrapa, do CNPq e da Fundação Banco do Brasil

${ }^{2}$ Embrapa Cerrados, BR 020, km, 18, Caixa Postal 8.223, Planaltina-DF, Brasil, 73.310-970, vieiraea@cpac.embrapa.br, ffaleiro@cpac.embrapa.br,

marilia@cpac.embrapa.br

${ }^{3}$ Pesquisador da Embrapa Cerrados, Planaltina-DF, Brasil, josefino@cpac.embrapa.br

${ }^{4}$ Estagiária da Embrapa Cerrados, Planaltina-DF, Brasil, bellon@cpac.embrapa.br
} 


\section{Introdução}

A mandioca (Manihot esculenta Crantz) é cultivada principalmente visando o aproveitamento de suas raízes tuberosas ricas em amido na alimentação humana, embora a cultura também seja produzida, em menor escala, para a alimentação animal e fins industriais que não envolvem a alimentação humana. Em razão de sua rusticidade, atualmente a espécie é uma importante fonte de calorias da dieta de vários países tropicais em desenvolvimento (COCK, 1985).

A mandioca apresenta potencial genético para ser fonte de carotenóides e licopeno para a alimentação humana. No caso dos carotenóides, em especial de $\beta$ caroteno, precursor da vitamina $\mathrm{A}$, presente em genótipos com raízes de coloração amarela (IGLESIAS et al., 1997; MEZZETE et al., 2009; NASSAR et al., 2007). O licopeno, presente em raízes de coloração rosada, exibe propriedades antioxidantes que protegem o corpo contra radicais livres (NASSAR et al., 2007). Nesse contexto, a possibilidade da mandioca ser além de fonte de calorias para as populações mais carentes do mundo, também ser fonte de vitamina A e licopeno permitiria melhorar a nutrição dos habitantes de países em desenvolvimento e agregar valor ás variedades destinadas ao consumo humano (WELSH; GRAHAM, 2002).

A possibilidade de agregação de qualidades nutricionais às raízes de mandioca destinadas à alimentação humana (biofortificação) direcionou os programas de melhoramento no sentido da seleção de clones de mandioca de mesa com coloração da raiz amarela, uma vez que existe uma correlação positiva entre a intensidade da coloração amarela das raízes e os teores de carotenóides das mesmas (CHÁVEX et al., 2005). A seleção de clones com coloração da polpa da raiz rosada que está associada à presença de licopeno também tem sido considerada no melhoramento genético (NASSAR et al., 2007).

Entretanto, para que qualquer programa de melhoramento genético logre êxito é necessária a existência de variabilidade genética para o(s) caracter(es) que se deseja melhorar. No Brasil, o provável centro de origem e de diversidade da mandioca (OLSEN, 2004), a variabilidade genética da espécie é elevada inclusive quanto à coloração da polpa das raízes (VIEIRA et al., 2008b). Estudos para quantificar a variabilidade genética existente entre acessos de mandioca com diferentes cores de polpa de raiz e, principalmente, entre acessos com a mesma cor de polpa de raiz são estratégicos para subsidiar programas de conservação e uso de germoplasma e programas de melhoramento genético.

Marcadores moleculares vêm sendo utilizados com eficiência na estimativa da variabilidade genética em mandioca (FERREIRA et al., 2008; VIEIRA et al., 2008a; ZACARIAS et al., 2004), pois apresentam ampla capacidade de acessar as informações contidas no genoma. Além dos marcadores, caracteres fenotípicos também são utilizados na caracterização de acessos (ALBUQUERQUE et al., 2009; NICK et al., 2008; VIEIRA et al., 2008a). Entretanto os marcadores moleculares apresentam a vantagem de não sofrerem influência ambiental. Dentre as diversas técnicas de marcadores moleculares, o RAPD (polimorfismo de DNA amplificado ao acaso) destacase, pelo baixo custo, rápida e fácil execução e por não exigir a síntese de iniciadores específicos (FERREIRA; GRATTAPAGLIA, 1998).

Neste trabalho, objetivou-se caracterizar por meio de marcadores RAPD 20 acessos de mandioca biofortificados com potencial de uso no melhoramento genético.

\section{Material e métodos}

Foram analisados 20 acessos de mandioca mantidos no Banco Regional de Germoplasma de Mandioca do Cerrado (BGMC), consistindo de: i) 10 acessos com cor da polpa da raiz amarela, incluído dois recomendados para o cultivo no nordeste brasileiro; ii) oito acessos com cor da polpa da raiz rosada, incluído um recomendado para o cultivo no nordeste brasileiro; e iii) dois acessos melhorados recomendados para o cultivo na região CentroSul do Brasil, sendo um com cor da polpa da raiz creme e outro com cor da polpa da raiz branca (TAB. 1).

O DNA dos acessos foi extraído a partir de folhas em estágio intermediário de maturação, por meio do método do CTAB, com modificações (FALEIRO et al., 2003) e quantificado por espectrofotometria a $260 \mathrm{~nm}$, sendo a relação A260/A280 utilizada para avaliar a pureza do DNA.

As reações para o obtenção dos marcadores RAPD foram realizadas em um volume total de $13 \mu \mathrm{L}$, contendo Tris-HCl 10 mM (pH 8,3), KCl 50 mM, $\mathrm{MgCl}_{2} 3$ mM, 100 $\mu \mathrm{M}$ de cada um dos desoxiribonucleotídios (dATP, dTTP, dGTP e dCTP), 0,4 $\mu \mathrm{M}$ de um iniciadores, uma unidade da enzima Taq polimerase e $15 \mathrm{ng}$ de DNA. No estudo foram utilizados 12 iniciadores decâmeros dos conjuntos Operon D (02; 08; 18), F (08), G (05;08; 09; 15; 16), H $(10 ; 16 ; 17)$. Na etapa de amplificação dos segmentos de DNA foi utilizado um termociclador programado para 40 ciclos, cada um constituído pela seqüência de 15 segundos a $94{ }^{\circ} \mathrm{C}, 30$ segundos a $35^{\circ} \mathrm{C}$ e 90 segundos a $72{ }^{\circ} \mathrm{C}$. Após os 40 ciclos, foi realizada uma etapa de extensão final de seis minutos a $72{ }^{\circ} \mathrm{C}$, e posteriormente, a temperatura foi reduzida para $4{ }^{\circ} \mathrm{C}$. Após a amplificação, 
Tabela 1 - Acessos de mandioca analisados com respectivos nomes comuns, locais de coleta/procedência (LCP) e coloração da polpa da raiz (CPR)

\begin{tabular}{|c|c|c|c|c|}
\hline Número & Acessos & Nome comum & LCP & CPR \\
\hline 1 & BGMC 1415 & Vermelha & Distrito Federal & rosada \\
\hline 2 & BGMC 1228 & Mirassol & Mato Grosso & rosada \\
\hline 3 & BGMC 1222 & Colorada & Distrito Federal & rosada \\
\hline 4 & BGMC 1229 & Vermelha Omar & Distrito Federal & rosada \\
\hline 5 & BGMC 1218 & Klainasik & Pará & amarela \\
\hline 6 & BGMC 1221 & Xingu & Pará & amarela \\
\hline 7 & BGMC 1231 & Sem denominação & Maranhão & amarela \\
\hline 8 & BGMC 1398 & 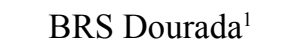 & Bahia & amarela \\
\hline 9 & BGMC 1397 & BRS Gema de Ovo $^{1}$ & Amazonas & amarela \\
\hline 10 & BGMC 1223 & Oricuri & Pará & amarela \\
\hline 11 & BGMC 1224 & Surubim & Pará & amarela \\
\hline 12 & BGMC 1226 & AC Vermelha & Pará & amarela \\
\hline 13 & BGMC 1227 & Pretinha & Pará & amarela \\
\hline 14 & BGMC 1374 & Vermelha Rio Preto & Distrito Federal & rosada \\
\hline 15 & BGMC 1225 & Precoce & Pará & amarela \\
\hline 16 & BGMC 1234 & BRS Rosada ${ }^{1}$ & Bahia & rosada \\
\hline 17 & BGMC 1235 & Sem denominação & Bahia & rosada \\
\hline 18 & BGMC 1278 & Patureba Vermelha & Minas Gerais & rosada \\
\hline 19 & BGMC 753 & IAC $756-70^{2}$ & IAC - São Paulo & creme \\
\hline 20 & BGMC 436 & IAC $12-829^{2}$ & IAC - São Paulo & branca \\
\hline
\end{tabular}

1= Recomendo para o cultivo pelo programa de melhoramento genético de mandioca da Embrapa Mandioca e Fruticultura Tropical, baseado em Cruz das Almas (BA); ${ }^{2}=$ Recomendo para o cultivo pelo programa de melhoramento genético de mandioca do Instituto Agronômico de Campinas (IAC), baseado em Campinas (SP)

foram adicionadas, a cada amostra, $3 \mu \mathrm{l}$ de uma mistura de azul de bromofenol (0,25\%) e glicerol (60\%) em água. Essas amostras foram aplicadas em gel de agarose (1,2\%), corado com brometo de etídio, submerso em tampão TBE (Tris-Borato $90 \mathrm{mM}$, EDTA $1 \mathrm{mM}$ ). A separação eletroforética foi de quatro horas, a 90 volts, ao término da qual os géis foram fotografados sob luz ultravioleta.

Os produtos das reações de amplificação (marcadores RAPD), que apresentaram elevada nitidez, passíveis de serem interpretados com precisão e com reprodutibilidade, foram classificados em presença (1) e ausência (0) de bandas e convertidos em uma matriz de dados binários, a partir da qual foi estimado: i) o conteudo de informação de polimorfismo (CIP) de cada iniciador, por meio da fórmula CIP $=2 \mathrm{f}_{\mathrm{i}}\left(1-\mathrm{f}_{\mathrm{i}}\right)$, onde fi é a freqüência de presença de banda (1), e (1-fi) é a freqüência de ausência de banda (0), e posteriormente foi estimado o CIP médio de cada iniciador por meio da média aritmética do CIPs obtidos (POWELL et al., 1996); ii) o índice do marcador (IM) calculado para cada iniciador por meio da fórmula IM = CIP x nbp, onde npb é o número de bandas polimórficas (POWELL et al., 1996); e iii) a similaridade genética entre os acessos, por meio do coeficiente de Jaccard, conforme a equação: $\mathrm{S}_{\mathrm{ij}}=\mathrm{N}_{\mathrm{ij}} /\left(\mathrm{N}_{\mathrm{ij}}+\mathrm{N}_{\mathrm{i}}+\mathrm{N}_{\mathrm{j}}\right)$; onde: $\mathrm{N}_{\mathrm{ij}}=$ número de bandas presentes em ambos os acessos $\mathrm{i}$ e j; $\mathrm{N}_{\mathrm{i}}=$ o número de bandas presentes no acesso $\mathrm{i}, \mathrm{e} \mathrm{N}_{\mathrm{j}}$ $=\mathrm{o}$ número de bandas presentes no acesso $\mathrm{j}$.

Com base na matriz de similaridade foi construído um dendrograma, por meio do método de agrupamento da distância média (UPGMA). O ajuste entre a matriz de similaridade e o dendrograma foi estimado pelo coeficiente de correlação cofenética (r), conforme Sokal e Rohlf (1962), por meio do programa computacional NTSYS pc 2.1 (ROHLF, 2000). A estabilidade dos agrupamentos foi computada por meio da análise de Bootstrap com 500 replicações por meio do programa Genes (CRUZ, 2001). Para complementar as informações do dendrograma, foi analisada a dispersão gráfica dos acessos baseada em escalas multidimensionais usando o método das coordenadas principais, com auxílio 
do Programa SAS (SAS INSTITUTE INC., 1989) e Statistica (STATSOFT INC., 1999).

\section{Resultados e discussão}

Os 12 iniciadores utilizados no estudo geraram um total de 144 bandas, sendo que destas 120 (83\%) foram polimórficas e 24 (17\%) foram monomórficas (TAB. 2). O número de bandas polimórficas $(\mathrm{BP})$ por iniciador variou de 17 (OPD-18) a 4 (OPH-10), o conteúdo da informação de polimorfismo (CIP), variou de 0,35 (OPG-09) a 0,10 (OPD-08) enquanto que o índice do marcador variou de 4,48 (OPF-08) a 0,48 (OPH-10). Esses resultados revelaram que $67 \%$ dos iniciadores empregados no estudo detectaram mais de sete bandas polimórficas por iniciador, os CIPs e IMs de $75 \%$ dos iniciadores foram superiores a 0,20 e 1,40, respectivamente, revelando o elevado poder descriminativo e a boa capacidade multiplex dos mesmos e a eficiência da técnica de RAPD em estudos de quantificação e organização da variabilidade genética em mandioca.

Os acessos mais similares geneticamente foram BGMC 1231 e a variedade de mandioca de mesa BGMC 1398 (BRS Dourada) ambos com cor da polpa da raiz amarela, sendo o primeiro procedente do estado do Maranhão e o segundo do estado da Bahia e recomendado para o cultivo comercial nas condições do Recôncavo Baiano e dos Tabuleiros Costeiros (FIG. 1). Os acessos menos similares, segundo a matriz de similaridade genética, foram o acesso com cor da polpa da raiz amarela
BGMC 1226 e a variedade melhorada de mandioca de indústria com cor da polpa da raiz branca BGMC 436 (IAC 12-829) que é recomendada para o cultivo na região Centro-Sul do Brasil.

Por meio da análise visual da Figura 1 foi possível dividir os acessos avaliados em 3 grupos: grupo I) formado pelos acessos com cor da polpa da raiz rosada BGMC 1415, BGMC 1222, BGMC 1228, BGMC 1229, BGMC 1234, BGMC 1235 e BGMC 1278 e os acessos com cor da polpa da raiz amarela BGMC 1225 e BGMC 1218; grupo II) formado pelos acessos com cor da polpa da raiz amarela BGMC 1231, BGMC 1398, BGMC 1397, BGMC 1223, BGMC 1224, BGMC 1226, BGMC 1227 e BGMC 1221 e o acesso com cor da polpa da raiz rosada BGMC 1374; grupo III) formado pelos acessos melhorados com cor da polpa da raiz creme BGMC 753 e com cor da polpa da raiz branca BGMC 436. O coeficiente de correlação cofenética do dendrograma $(r=0,93)$ revelou o elevado ajuste entre a representação gráfica da similaridade genética e a matriz de similaridade, o que justifica que sejam realizadas inferências por meio da avaliação visual da Figura 1.

Dentre os acessos do grupo I apresentaram porcentagens de agrupamento coincidentes superiores a $70 \%$ segundo a técnica de bootstraping, os acessos com coloração da polpa da raiz rosada BGMC 1415 e BGMC 1222 e o com a polpa da raiz amarela BGMC 1218, bem como os acessos com coloração da polpa da raiz rosada BGMC 1228, BGMC 1229, BGMC 1234, BGMC 1235 e BGMC 1278 (FIG. 1). Já no grupo II apresentaram porcentagens de agrupamento coincidentes superiores a $70 \%$ segundo a técnica de bootstraping os

Tabela 2 - Iniciadores utilizados e suas respectivas sequências, número de bandas polimórficas (BP), número de bandas monomórficas (BM), conteúdo de informação de polimorfismo (CIP) e indíce do marcador (IM)

\begin{tabular}{|c|c|c|c|c|c|}
\hline Iniciadores & Sequência $5^{\prime} \rightarrow 3^{\prime}$ & $\mathrm{BP}$ & $\mathrm{BM}$ & CIP & IM \\
\hline OPD-02 & GGACCCAACC & 6 & 0 & 0,22 & 1,32 \\
\hline OPD-08 & GTGTGCCCCA & 8 & 4 & 0,10 & 0,80 \\
\hline OPD-18 & GAGAGCCAAC & 17 & 4 & 0,14 & 2,38 \\
\hline OPF-08 & GGGATATCGG & 16 & 2 & 0,28 & 4,48 \\
\hline OPG-05 & CTGAGACGGA & 11 & 2 & 0,23 & 2,53 \\
\hline OPG-08 & TCACGTCCAC & 11 & 0 & 0,27 & 2,97 \\
\hline OPG-09 & CTGACGTCAC & 11 & 0 & 0,35 & 3,85 \\
\hline OPG-15 & ACTGGGACTC & 6 & 2 & 0,28 & 1,68 \\
\hline OPG-16 & AGCGTCCTCC & 7 & 3 & 0,22 & 1,54 \\
\hline OPH-10 & CCTACGTCAG & 4 & 3 & 0,12 & 0,48 \\
\hline OPH-16 & TCTCAGCTGG & 13 & 2 & 0,31 & 4,03 \\
\hline OPH-17 & САСТСТССТС & 10 & 2 & 0,27 & 2,70 \\
\hline TOTAL & 120 & 24 & - & - & \\
\hline
\end{tabular}




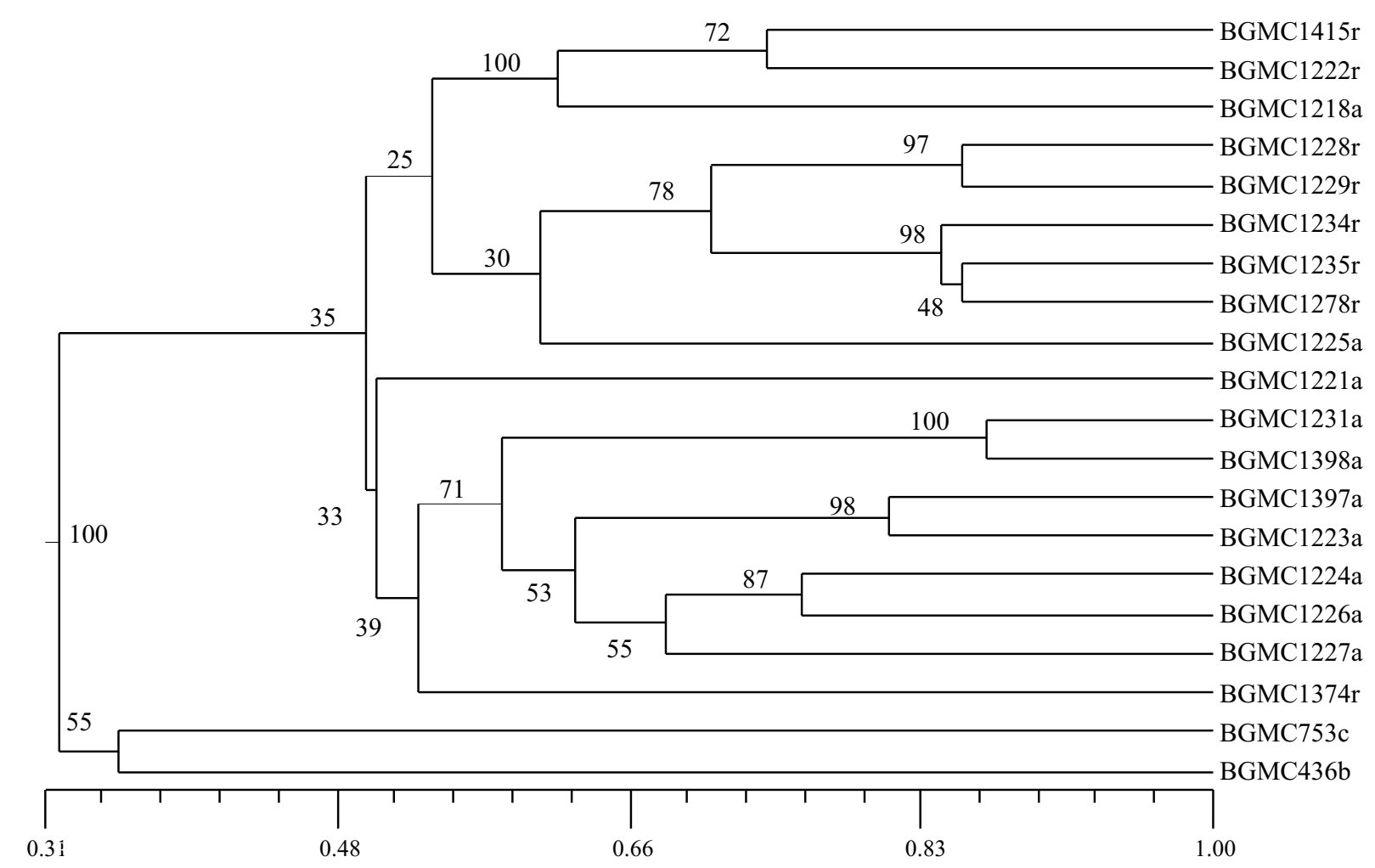

Figura 1 - Dendrograma resultante da análise de 20 acessos de mandioca, obtido pelo método de agrupamento UPGMA, com base na matriz de similaridade genética obtida por meio do coeficiente de Jaccard. Os valores encontrados nos grupos indicam o valor percentual de vezes que os genótipos agruparam juntos em 500 ciclos de análise de bootstraping. O valor do coeficiente de correlação cofenética (r) é de 0,93

acessos com coloração da polpa da raiz amarela BGMC 1231, BGMC 1398, BGMC 1397, BGMC 1223, BGMC 1224, BGMC 1226 e BGMC 1227 (FIG. 1). A análise da dispersão gráfica dos acessos obtida com base na matriz de dissimilaridade (FIG. 2) evidencia uma tendência de agrupamento dos acessos com base na cor da polpa da raiz, o que também pode ser verificado no dendrograma. Entretanto, no gráfico de dispersão, pode-se observar que o acesso com cor da polpa da raiz rosada BGMC 1374 que se agrupou no dendrograma com os acessos com cor da polpa da raiz amarela, e o acesso com cor da polpa da raiz amarela que se agrupou com os acessos com cor de polpa da raiz rosada ocupam uma região intermediária entre esses dois grandes grupos.

Do ponto de vista da conservação de germoplasma os resultados mostraram que não existem duplicatas entre os acessos avaliados e que, portanto é necessária a manutenção no BGMC de todos os acessos avaliados, a fim de garantir a conservação das combinações genéticas para uso no melhoramento genético de mandioca. Esse cenário de existência de variabilidade aponta no sentido de também haver variação quanto ao potencial agronômico no grupo de acessos avaliados, e que essa variação pode ser utilizada no melhoramento genético de mandioca visando ao desenvolvimento de novas variedades de mandioca de mesa biofortificadas. Nesse sentido, é fundamental que sejam realizados estudos, visando a caracterização morfológica, agronômica e bioquímica desses acessos, possibilitando assim a geração de um volume grande de informações técnicas para subsidiar os pesquisadores no momento da tomada de decisão a cerca de quais acessos utilizar como genitores.

Não foi observada tendência de agrupamento dos acessos em função do local de origem/procedência tendo sido detectados agrupamentos de acessos de diferentes locais (TAB. 1 e FIG. 1). Essa ausência de estruturação da diversidade genética pode ser explicada pelo fato da haver uma constante troca de genótipos entre os produtores de diferentes regiões o que gera dificuldades na identificação da origem exata dos acessos e possibilita a recombinação genética entre acessos de diferentes origens (COLOMBO et al., 2000; DUPUTIÉ et al., 2009; ZACARIAS et al., 2004).

As duas variedades de mandioca melhoradas oriundas do programa de melhoramento genético de 


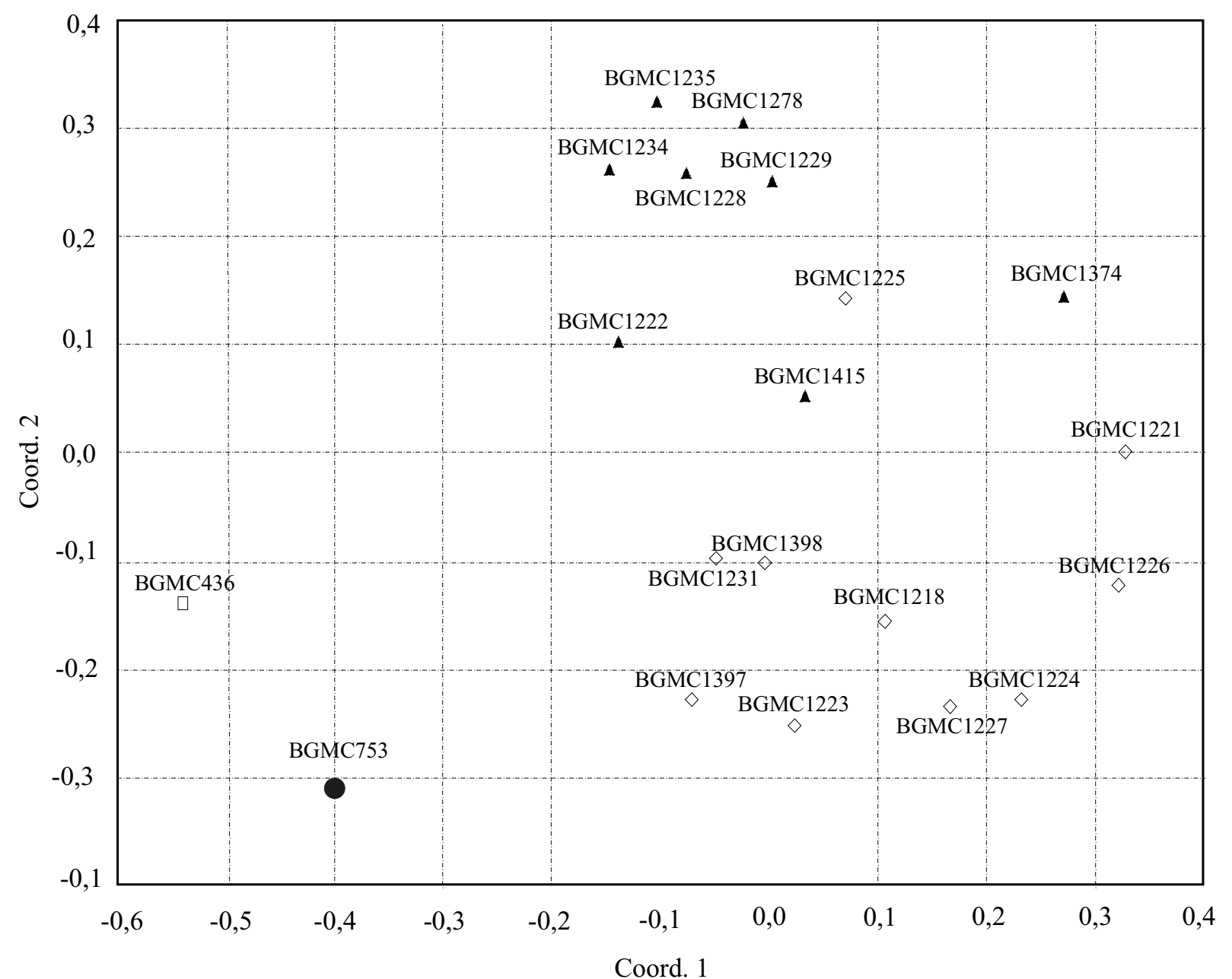

Figura 2 - Dispersão gráfica de 20 acessos de mandioca, com coloração de polpa de raiz rosada $(\boldsymbol{\Delta})$, amarela $(\diamond)$, creme $(\bullet)$ e branca ( $\square$ ) obtida com base na matriz de dissimilaridade genética obtida por meio do complemento do coeficiente de Jaccard

mandioca do Instituto Agronômico de Campinas BGMC 753 (IAC 576-70) e BGMC 436 (IAC 12-829) revelaram elevada diferenciação genética em nível de DNA entre si e em relação aos demais acessos avaliados, o que revela que o backgroud genético desses é bastante diferenciado dos demais acessos avaliados (FIG. 1 e 2). Do ponto de vista do melhoramento de mandioca para a biofortificação, esse resultado indica que o acesso BGMC 753 pode ser utilizado como genitor em cruzamentos com os demais acessos avaliados, por evidenciar elevado potencial produtivo e boas qualidades culinárias na região Centro Sul do Brasil (FIALHO et al., 2009; MEZETTE et al., 2009), objetivando a combinação dos genes que conferem as boas qualidades do acesso BGMC 753 com os genes que controlam os teores de $\beta$-caroteno e licopeno nas raízes dos acessos biofortificados.

Em relação à organização da variabilidade genética, a tendência de agrupamento em função da coloração da polpa da raiz necessita ser mais estudada, por meio de estudos que elucidem a origem destes acessos ou das mutações que permitiram o acúmulo de carotenóides nas raízes de mandioca e se realmente esses acessos evoluíram de forma independente a ponto de apresentarem estruturação genética. Outra linha de pesquisa a ser explorada é a que trata da herança do acúmulo de $\beta$ caroteno e licopeno o que é fundamental para a definição das estratégias de melhoramento.

\section{Conclusão}

Os marcadores RAPD mostraram eficiência na determinação da variabilidade genética entre acessos de mandioca com cor da polpa da raiz amarela, rosada, creme e branca, diferenciaram os acessos melhorados dos demais acessos e revelaram uma tendência de 
separação dos acessos com cor da polpa da raiz rosada dos com cor da polpa da raiz amarela.

\section{Agradecimentos}

Os autores agradecem à Embrapa, Fundação Banco do Brasil e ao CNPq pelo apoio financeiro.

\section{Referências}

ALBUQUERQUE, J. A. A. et al. Caracterização morfológica e agronômica de clones de mandioca cultivados no Estado de Roraima. Revista Brasileira de Ciências Agrárias, v. 04, n. 04, p. 388-394, 2009.

CHÁVEZ, A. L. et al. Variation of quality traits in cassava roots evaluated in landraces and improved clones. Euphytica, v. 143, n. 01, p. 125-133, 2005.

COCK, J. Cassava: new potential for a neglected crop. Boulder: Westview Press, 1985. 240 p.

COLOMBO, C. et al. Diversity within American cassava germplasm based on RAPD markers. Genetics and Molecular Biology, v. 31, n. 01, p. 189-199, 2000.

CRUZ, C. D. Programa genes: aplicativo computacional em genética e estatística. Viçosa: UFV, 2001. 648 p.

DUPUTIÉ, A. et al. Traditional Ameridian cultivators combine directional and ideotypic selection for sustaineble management of cassava genetic diversity. Journal of Evolutionary Biology, v. 22, n. 06, p. 1317-1325, 2009.

FALEIRO, F. G. et al. Metodologia para operacionalizar a extração de DNA de espécies nativas do cerrado. Planaltina: Embrapa Cerrados, 2003. 6 p. (Comunicado Técnico, 92).

FERREIRA, C. F. et al. Molecular characterization of cassava (Manihot esculenta Crantz) with yellow-orange roots for beta-carotene improvement. Crop Breeding and Applied Biotechnology, v. 08, n. 01, p. 23-29, 2008.

FERREIRA, M. E.; GRATTAPAGLIA, D. Introdução ao uso de marcadores moleculares em análise genética. Brasília: EMBRAPA-CENARGEN, 1998. 220 p.

FIALHO, J. de F. et al. Desempenho de variedades de mandioca de mesa no Distrito Federal. Revista Brasileira de Agrociência, v. 15, n. 01-04, p. 31-35, 2009.
IGLESIAS, C. et al. Genetic potencial and stability of carotene content in cassava roots. Euphytica, v. 94, n. 03, p. 367-373, 1997.

MEZETTE, T. F. et al. Seleção de clones-elite de mandioca de mesa visando a características agronômicas, tecnológicas e químicas. Bragantia, v. 68, n. 03, p. 601-609, 2009.

NASSAR, N. et al. Cassava Diversity in Brazil: the case of carotenoid-rich landraces. Genetics and Molecular Research, v. 06, n. 01, p. 116-121, 2007.

NICK, C. et al. Genetic dissimilarity in cassava clones determined by multivariate techniques. Crop Breeding and Applied Genetics, v. 08, n. 02, p. 104-110, 2008.

OLSEN, K. M. SNPs, SSRs and inferences on cassava's origin. Plant Molecular Biology, v. 56, n. 04, p. 517-526, 2004.

POWELL, W. et al. The comparison of RFLP, RAPD, AFLP and SSR (microsatellite) markers for germplasm analysis. Molecular Breeding, v. 02, n. 03, p. 225-238, 1996.

ROHLF, F. J. NTSYS-pc: numerical taxonomy and multivariate analysis system, version 2.1. New York: Exeter Software, 2000. 98 p.

SAS INSTITUTE INC. SAS/Stat User's Guide Version 6. 4. ed. Cary: Sas Institute Inc., 1989. 943 p.

SOKAL, R. R.; ROHLF, F. J. The comparison of dendrograms by objective methods. Taxon, v. 11, n. 01, p. 30-40, 1962.

STATSOFT INC. Statistica for Windows [Computer program manual]. Tulsa: StatSoft Inc. 1999. 2 CDs.

VIEIRA, E. A. et al. Divergência genética entre acessos açucarados e não açucarados de mandioca. Pesquisa Agropecuária Brasileira, v. 43, n. 12, p. 1707-1715, 2008a.

VIEIRA, E. A. et al. Variabilidade genética do banco de germoplasma de mandioca da Embrapa Cerrados acessada por meio de descritores morfológicos. Científica, v. 36, n. 01, p. 56-67, 2008b.

WELCH, R. M.; GRAHAN, R. D. Breeding crops for enhanced micronutrient content. Plant and Soil, v. 245, n. 01, p. 205-214, 2002.

ZACARIAS, A. M. et al. Characterization and genetic distance analysis of cassava (Manihot esculenta Crantz) germplasm form Mozambique using RAPD fingerprinting. Euphytica, v. 138, n. 01, p. 49-53, 2004. 